\title{
Utilizing the ATM technology in E-distance learning
}

\author{
Inaam Abbas Hieder ${ }^{1}$, Sara Mohammad Abdullah ${ }^{2}$, Rawaa Ahmed Ali ${ }^{3}$ \\ ${ }^{1,3}$ Department of Computer Science, College of Medicine, University of Baghdad, Iraq \\ ${ }^{2}$ Department of Medical Journal, College of Medicine, University of Baghdad, Iraq
}

\begin{tabular}{l}
\hline \hline Article Info \\
\hline Article history: \\
Received Jan 23, 2020 \\
Revised Apr 24, 2020 \\
Accepted Mar 18, 2020
\end{tabular}

Keywords:

ATM (Asynchronous transfer mode)

E-Learning (Electronic

learning)

\begin{abstract}
There is an Increasing demand for the education in the field of E-learning specially the higher education, and to keep contiuity between the user and the course director in any place and time. This research presents a proposed and simulation multimedia network design for distance learning utilizing ATM technique. The propsed framework determines the principle of ATM technology and shows how multimedia can be integrated within E- learning conteext. The first part of this research presents a theoretical design for the Electricity Department, university of technology. The purpose is to illustrate the usage of the ATM and Multimedia in distance learning process. In addition, this research composes two entities: Software entity by using image, sound and a mix between them to be transfered across the ATM network.. The MATLAB was used to validate the implementation of the required design objectives: (hardware entity) where a prototype is designed (experimental trial), which aims to carry out the connectivity process between the user and course director, where multiple PCs are connected via unshielded twisted pair (UTP) and a web camera with microphone have been attached to PCs. To finalize this stage, an interface is implemented to show the data transmission process for multimedia by the ATM network and it has been realized through the Visual Basic language. Finally, to validate the level of success by using the ATM technique, some important factors have been determined through the analysis phase, which are: time delay, throughput and efficiency. The propsed design manages to minimize the impat of noise and improve the throuput ratio by $30 \%$ while minizing the delay with a ratio of $22 \%$.
\end{abstract}

Copyright () 2020 Institute of Advanced Engineering and Science. All rights reserved.

\section{Corresponding Author:}

Sara Mohammad Abdullah,

Department of Medical Journal, College of Medicine,

University of Baghdad, Iraq.

Email: saraheng86@gmail.com

\section{INTRODUCTION}

In general, the concept of e-learning utilizes various sorts of technologies to provide learningteaching facilities through the Internet in an electronic form. Majority of universities and institutions of higher educations are employing advanced communication and IT techniques to make their academic material remotely accessible for all intended users. Hence, students can access their required academic courses in distance via different technological methods. Several approaches have been presented to realize successful remote learning. In 1994, course delivery through ICT and internet technologies has started. Accordingly, several structural methods that rely on the new class of course management started to appear and adapted in education. Since then, remote education steadily and slowly grown and becomes one of the common teaching techniques. In 2010, $30 \%$ of postsecondary students in U.S. were enrolled with at least one online course in the last two decades, there were a significant increase in the number of higher educational institutions that offer E-learning programs and there were a significant growth of e- learning enrollment in most countries who adopt this technology. [1] The Asynchronous transfer mode (ATM) is a technique that 
has been used widely in the structure of the broadband ISDN. Basically, it is an evolution of packet switching process. Recent amendments in the hierarchy of the marketing conditions and telecommunications industries have emerged new challenges and opportunities for the service providers and networks operators. Networks that are mainly designed to support enhanced voice services are being under developing process to tackle the challenges of multimedia complications and pressures of competitiveness. ATM technology, one of the recognized technologies of public network in present, recently has enormous service providers in the world wide that present ATM-based services. The advantage of utilizing the benefit of the ATM technique inside the public network can support the carriers with strategic competitive feature. According to the International Telecommunications Union (ITU) [2].

The ATM has a defined set of signaling standards and international interface. Due to the rapid changes in the educational requirement of the society, recently it is not enough to have an educational system attached to a single point of time. Meanwhile, the education system has to be a lifelong continuous process that permits people especially those in the technical fields to stay up to date with their changing disciplines $[3,4]$. Mobile distance learning as modern distance learning [5]: On the other hand, mobile learning is one of the most important technology of modern E- distance education. It provides an integration of Text, sound, image, video, animation and other educational resources together. To be transferred to the user. It is not only to solve the defect of the traditional educational resources however, it can provide the users with learning resources anywhere and anytime. a quick and convenient services that support learning interactive are required in the future of $\mathrm{E}$-learning hence, mobile learning assists the "interaction" since the interaction have its important role in the E-learning process. Mobile learning can support online evaluation function hence, provides better personal assessment to the progress of the student.

Utilizing E-learning has the advantage of serving students in different time hence, the learning process of each student does not disrupt with others. However, e-learning usually has a uniform learning scenario for all students. But as a solution a personalization features can be added to the e-learning system hence students can acquire leaning scenario that fits the learning style of each students. [6]

Synchronous and asynchronous e-learning due to the usage of the sensitive and advanced tools that empowers the e-learners to utilize these tools to support each e-learners' preferences. This process, the learning environment personalization, emphasized by any up to date educational theories. recently, one of the most significant criteria for identifying each individual differences in the process of learning is, preference of learning style In which adaptability criteria have been considered.Methods of supplying econtent in an on-line classroom, instructors, learners, interactive tools, modes of interaction and many other elements in online mastering modes are classified into two modes including synchronous and asynchronous e-learning. This phase focuses on the stated modes and some worried issues. Synchronous e-learning have been increased due to proven demands in a number of eras such as education. Autthors in [7, 8] concluded that e-learning embedded features in LMS will assist the tutor to generate a strategic learning features to suite the students' skills and style of learning, An interactive features of knowledge sharing, communication and information desimmination can be attained from utilizing e-learning.active learning can be achieved from differnet platforms like LMS, website, online database and social media platforms to enhance students' knowledge and discover different skills.

In the on-line educational environment, there is no bodily meeting. Synchronous and Asynchronous getting to know tools, such as threaded discussions, on the spot messaging and blogs, play a vital role in humanizing on line guides by way of replicating the school room journey of data trade and social construct, not simply between beginners and instructors however amongst the learners as well. People may just know it with the aid of reference to a particular vendor, tool or software application that enables the creation and shipping of synchronous e-Learning. Synchronous e-learning is live, real-time (and generally scheduled), facilitated instruction and learning-oriented interaction. In this kind of learning, gaining knowledge of experiences are live and real-time. The roots of synchronous e-learning are derived from three fundamental influences: the classroom, the media, and the conference. Synchronous e-learning can be defined as "Interact of participants with an instructor by means of the Web in actual time" Asynchronous on-line learning is described variously due to some components, its nature and facilities that are common in some characteristics. On the other hand, one of the famous definitions that center of attention on the elements of asynchronous e-learning introduced it as "an interactive studying community that is no longer constrained via time, area or the constraints of a classroom". Asynchronous e-learning is comparable to synchronous elearning which is a learner-centred method which uses on-line gaining knowledge of assets to facilitate information sharing regardless of the constraints of time and place amongst a community of people. Asynchronous e-learning takes benefit of computer-mediated communication (CMC) to obtain the guarantees of gaining knowledge of "anytime and anywhere" thru asynchronous online discussions. Asynchronous elearning is on the groundwork of constructivist theory, a learner-centred method that emphasize on the significance of peer-to-peer interactions. This approach combines self-study with asynchronous interactions 
to promote learning, and it can be used to facilitate getting to know in normal on-campus or regular education, distance schooling and continuing education. This combined community of novices and the digital community in which they talk are referred to as an asynchronous e-learning network. The prerequisites and elements using the Asynchronous e-learning are exclusive so, this technique is described through every other component [9].

Learning/teaching that utilizes from an asynchronous mode has been the predominant form of eleaning due to its flexibility. Asynchronous mode can deliver material in the format of video /audio lectures, articles, presentation to the e-learners. An access to these materials can be achieved via Learning Management System (LMS) anywhere and anytime. LMS is a number of tools that enables course content and delivers a framework for students and teachers communication like a classroom.VLE (Virtual Learning Environment, CMS(Course management system) are another terms which have been used in the same concept. Usually educational institution develops their private LMS while others depends on an open source or purchasing an LMS [10].

\subsection{Related work}

Authors in [11] concluded that by adding pattern management tubes and interactive quiz to BLS (blended learning system) and the use of BLESS (Blended Learning System Structure) has improved the learning system and an extension program can be achieved. Moreover, usability improvement is realized from The BLESS implementation on BLS.

Authors in [12] presented a load balancing clustering (LBC) technique that is provided to the Moodle LMS in order to mitigate the issue of poor performances in higher institution. The paper depended on keepalived and HAProxy tools in order to support the implemented LBC configuration for providing better performances of the e-learning system.

Meanwhile, authors in [13] focused on the possible challenges faced by novice programmers. The proposed model is based on creating animated lessons for computer science courses that can be supported by visual aids. The model is applied in two stages which will in turn enrich the e-learning activity and remove any possible obstacles.

Authors in [14] utilizes the packet trarcer in designing an electronic exam and sharing file system. This aids obtaining an enhanced environment for monitering and controlling an electronic learning system.

Meanwhile, authors in [15] have devised two models for applying efficient e-learning system. The models are tutor-student model which focuses student and tutor while the second model ismoderatingmember-secretary that concetrates in the role of secretary and the coordinator. The implemented technique has manged to achieve an effiecient collaoborated environment between members in an electroninc version.

An online learning environment called Intelligent Online Assessment and Revision (I-OnAR) has been proposed in [16]. The presented system provides an e-learning system with several phases as exam creation, revision and feedback analysis. A Rule-based machine learning technique has been utilized by the intelligent system to provide adaptive capabilities that support an improved electronic-based learning system.

The objective of this paper is to identify the efficiency of the ATM technonlgy in enhancing the transmission of video/audio signals regarding an E-learning system within the department of Electrical ad electronic engineering / University of Technology. The Issue here in the department of electrical ad electroning engineering is how to mitigate the impact of signal noise and how to determine the optimum strategy that provides efficient and reliable multimedia transmission for the E-learning.

\section{RESEARCH METHOD}

ATM network operation, The ATM network is basically composed of multiple ATM switches that are connected together through point to point ATM interfaces or links. The ATM switches provides two types of interfaces which are Network-to-Network Interface (NNI) and User Network Interfaces (UNI). UNI attaches the ATM endpoint devices (as routers, hosts, etc...) to the ATM switch while the NNI is used to connect two switches of ATM. According to where the switch is located in the premises and publicly owned, the NNI and UNI can be additionally classified into private and public NNI and UNI [2, 17]. The private UNI is responsible for connecting the private ATM switch to the end point ATM while the public part connects private switch or ATM endpoint to public switch. In addition, two switches inside a private organization can be connected by a private NNI. Meanwhile, inside a public organization, two ATM switches can be connected through a public one. Furthermore, two public switches for various service providers can be connected via a Broadband Inter carrier Interface (B-ICI). Figure 1 demonstrates the specifications of the ATM interface for both public and private network $[17,18]$. 


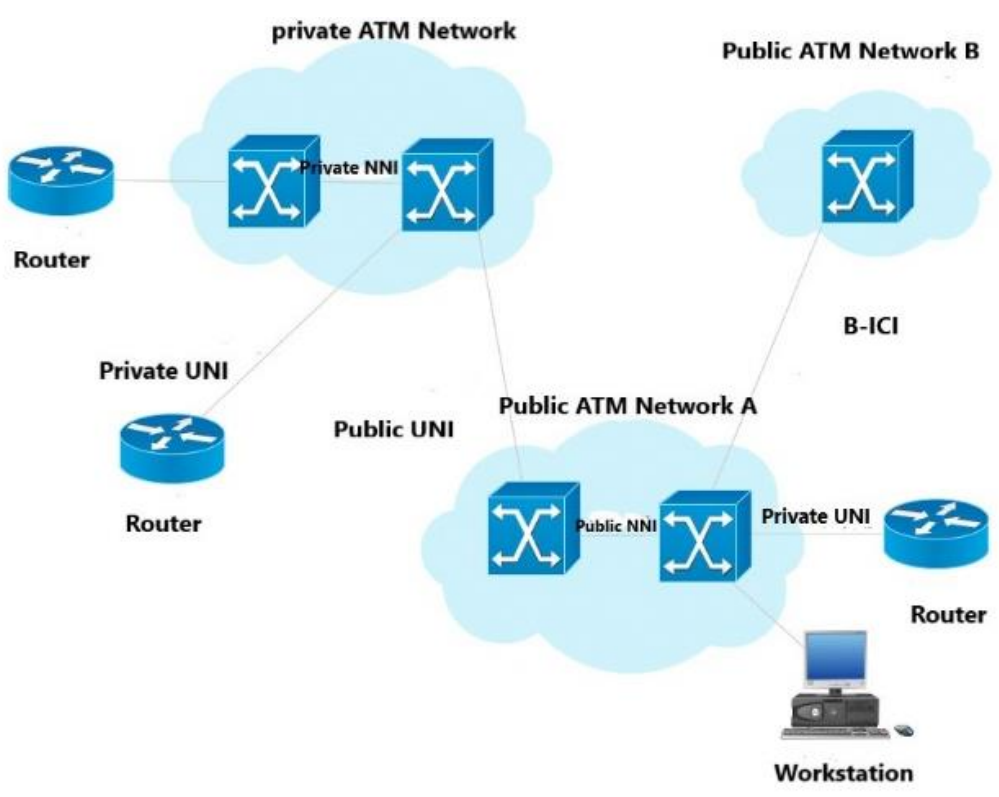

Figure 1. The specification of ATM interface for public and private networks

\subsection{Basic format of the ATM cell}

The asynchronous transfer modes make use of fixed sized cells consisting of a 5-bytes header and 48- bytes information field. There are several advantages to use of small sized fixed cells. It reduces queuing delay for a high priority implementation of switching mechanism in hardware [19]. The data can encompass of 4-byte of ATM adaptation layer and 44-byte of the real data. In the control section of the header, a bit can set the data either to 44 or 48 bytes. A fixed, small length of cells are more convenient to carry the voice and video traffic one reason for that is an intolerance of delays for such a traffic which result from waiting to download a large packet of data. Figure 2 demonstrates the fundamental format of ATM cell.

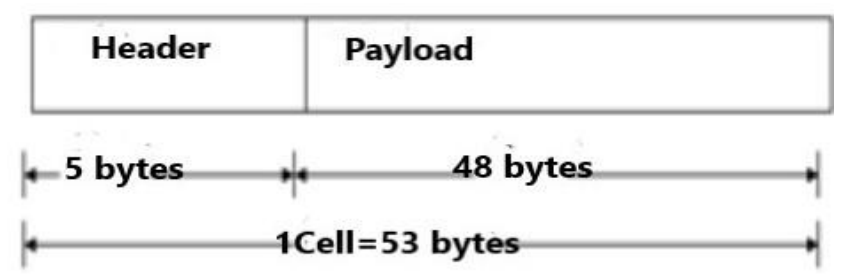

Figure 2. The header and payload data of an ATM cell

\subsection{ATM Cell- header (format and fields) header format and fields of ATM cell}

The ATM technology consists of 53 byte for transmission, switching and multiplexing unit, which is a fixed length cell or packet. ATM cell consists of two formats, the use of each of these formats depends on their position used within the network. The UNI cell format transport the traffic between the ATM network and the end user while the NNI cell format can carry the internetworking traffic. However, the two ATM cell format have the same size of 53-bytes with the payload of 48-bytes and a header of 5 bytes. Figure 3 illustrates the four bit of Generic Flow Control (GFC) parameter allocated in the UNI cell format which is the only differences with the other format. In the NNI cell format it is replaced by additional Virtual Path Identifier (VPI) field [20, 21].
a) GFC: Generic Flow Control
b) VPI : Virtual Path Identifier
c) VCI : Virtual Channel Identifier
d) PT : Payload Type 
e) CLP: Cell Loss Priority- if CLP $=1$ this means low priority to loss, otherwise when CLP $=0$ the cell is high priority to loss

f) HEC: Header Error Control- Error detection (and limited correction)

g) At the Network-to-network interface (NNI), the VPI is 12 bits long; its four most significant bits displace the GFC.

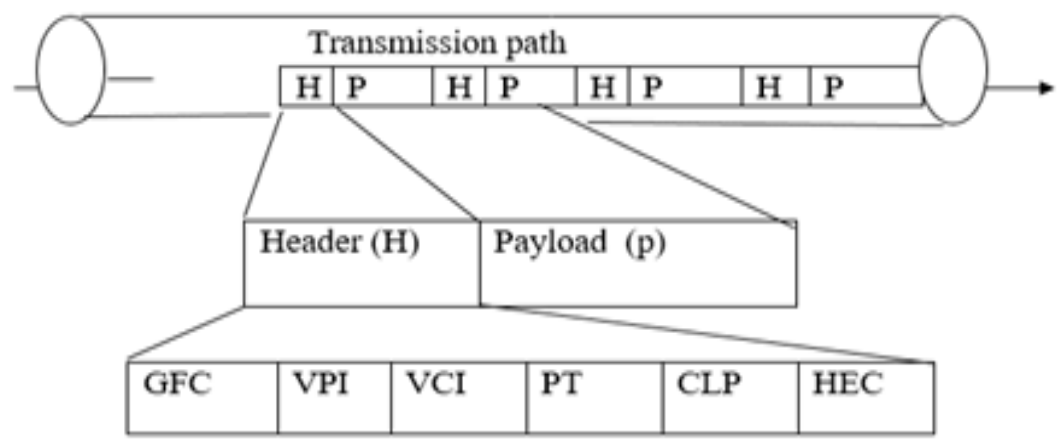

Figure 3. ATM cell format (UNI \& NNI cell format)

\subsection{Constant bit rate (CBR)}

This class is utilized to simulate circuit switching such that the transmission rate of a cell is constant. The cell loss rate (CLR) is considered for cell loss priority (CLP) $=0$ cells where it might be or might be not defined for $\mathrm{CLP}=1$ cell. Variety of applications that relies on CBR like: - Video/Audio distribution (as distance learning, television). - Video/Audio retrieval (as audio library, video on demand). - Video conferencing.

\subsection{Multimedia applications over ATM}

The multimedia applications which consists of data, voice and video traffics, each of them are different in their nature and can be utilized at the terminal equipment's (TE), Figure 4 illustrates the TE traffic configuration. [22]

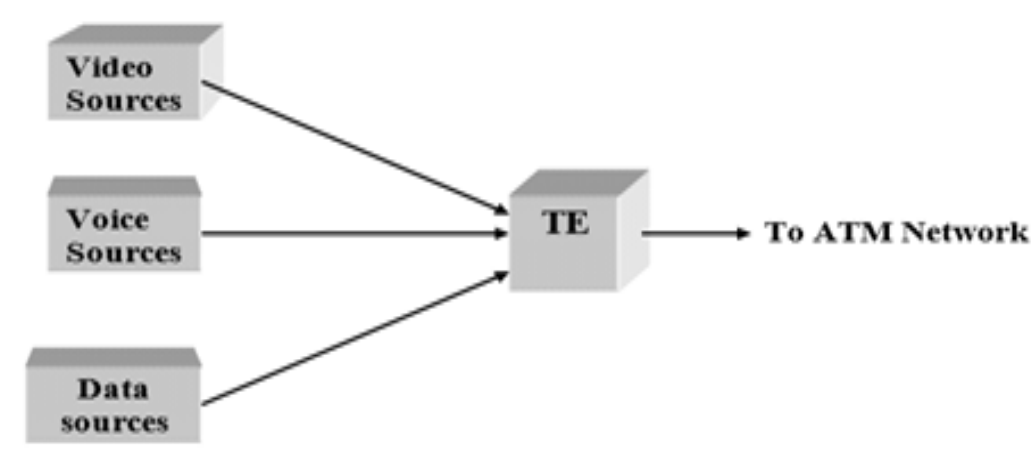

Figure 4. TE traffics configuration

\subsubsection{Voice traffic}

In Figure 5 describes a station block diagram which encodes and sends a voice stream. Usually the voice source uses a continuous time; coders are used to digitize the analog signal. [23] The produced samples are gathered in a packetize, a header is attached, when the sampling number in the packetize reached to the length of the predetermined cell, after that the process of generated a voice cell might be synchronized to an external timing. A transmit buffer is used to store the generated cells to be waiting for their transmission. However, in some LAN, the transmission of voice samples are done directly through out an assigned TDM 
(Time Division Multiplexing) channel over the network. The majority of other LAN protocols, the transmission of voice are achieved in the form of cells in which every cell comprises of a number of voice samples in a marketization interval. The end to end time delay of the voice cell must be within the range of 250-600ms. In Voice communication (telephone service), the transmitted information have to be carried in a transparent way to the receiver side similar in ATM (conventional line switching). The $16 \mathrm{khz}$ and embedded pulse code modulation (PCM) is utilized as the encoding method for each voice source sampling. Hence, the coding ratio is 4 bits/sample of $64 \mathrm{Kbps}$ of source peak ratio.

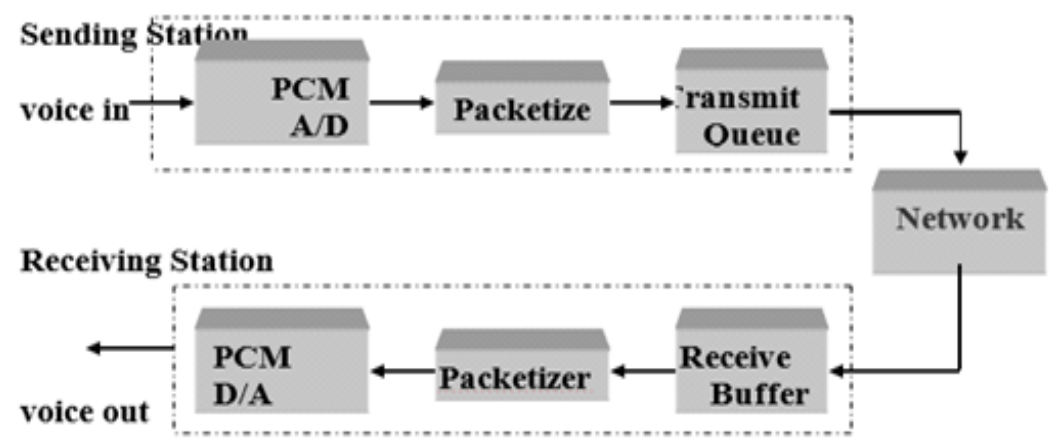

Figure 5. Block diagram of a station that encodes and sends a voice stream

\subsubsection{Video traffic}

According to a standard coding like H.261 or MPEG (Motion Picture Expire Group) is utilized to encode the video stream [24]. The frame division comprises of a number of $16 \times 16$ "Macro block" and each macro block differentially coded according to the previous frame, fin addition, in MPEG, differential coded will be done according to the previous and next frame. A station block diagram of end coding and sending a video stream over a network is shown as in Figure 6. [23, 25]. A video camera is used to take the frame and will be send as analog signal in to the grabber of the frame, where it will be digitized. After that, it will be compressed using the encoder. In order to minimize the variations issue in the output of an encoder, a rate buffer is used which in turn the encoder creates a constant bit rate stream.

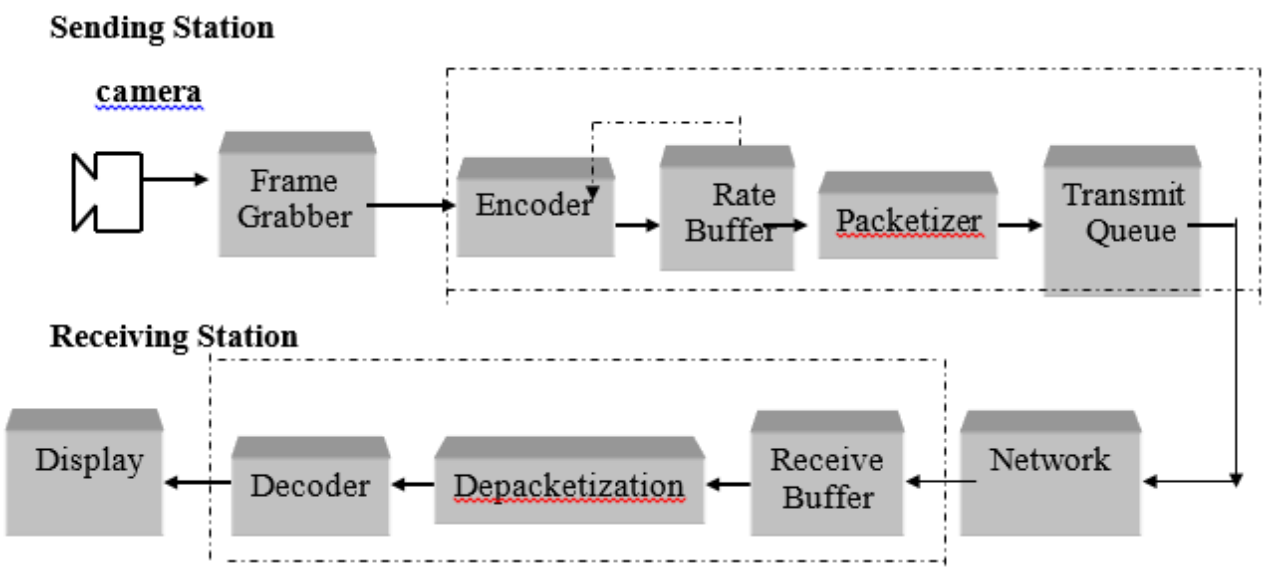

Figure 6. Block diagram of station that encoded and sends a video stream

To control the output rate as feedback of the encoder, the encoder uses the buffer occupancy. Hence, improving quality by preventing the rate buffer from being over or under flow. From the rate buffer the stream of constant bit rate is passed to the main memory via the system bus. The pocketsize stream of the sending station (as cells) is applied, in order to send streams over the networks. The cells are transmitted to the destination station over the network. The received cell is buffered by destination station in order to compensate the variation delay results from the network. 


\section{PROPOSED METHOD}

This section will highlight the posed model by which to design and implemt the ATM-based elearning system and to tackle the possible issues raised by different factors as the noise and the required quality for multimedia.

\subsection{Multimedia network design for the electricity department}

Multimedia represents the most recent technical development which incorporated as an aid to the educational process and in the business world. Transmission of multimedia content requires a high-speed network such as ATM for services such as video conference, video on demand and audio. Due to the growth of high-speed network like ATM technique and the advent of the latest video coding, today It is possible to transfer high data that generating multimedia services in real time, The ATM forum has standardized the transfer of compressed video over backbone of ATM networks. [26] Transportation of compressed video over ATM backbone networks has already been standardized by the ATM forum [26]. In order to achieve a better learning experience and improve the management competencies of the Department of Electricity, this research proposes a multimedia network for distance learning using ATM technology. The design focuses on the first floor, as shown in Figure 7. The researcher developed a simple design for the electricity department by placing the presentation in the lab. This room has a personal computer that communicates overhead with the slide panel, camera and microphone. Each room has a camera and a microphone. This design uses bidirectional video and bidirectional audio to get interactive between course director and student. The cable used to connect all devices is UTS (Unshelled Twisted Pair). Figure 7 shows the building blocks consisting of one floor, and the interconnections are achieved using axes. Connections between floors are switched using ATM 155 Mbps.

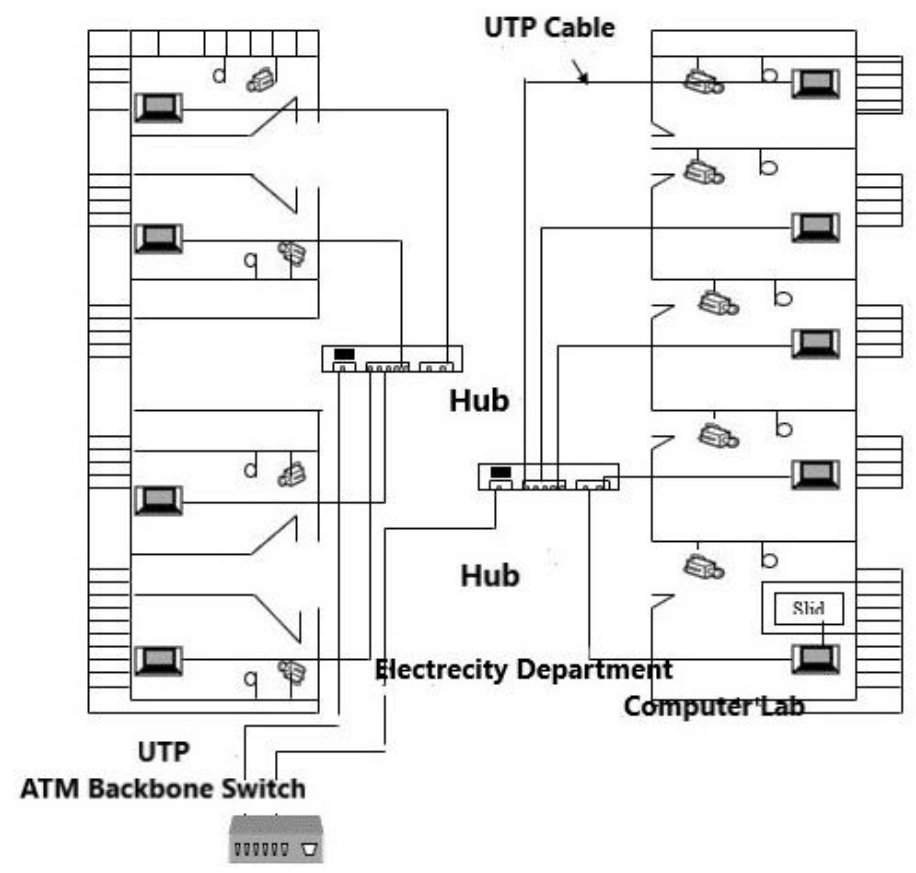

Figure 7. Multimedia network design using ATM Switch for the department of electricity

\subsection{Design multimedia network using ATM technique}

This section involves engineering and instructional procedures. The engineering procedures include two parts. Software design. Hardware implementation of the prototype for distance learning. a. Software Design Software package is designed and build for transmission and reception of multimedia (image, sound) over ATM network. The software was written by using (MATLAB). The block diagram of the designed network is shown in Figure 8. 


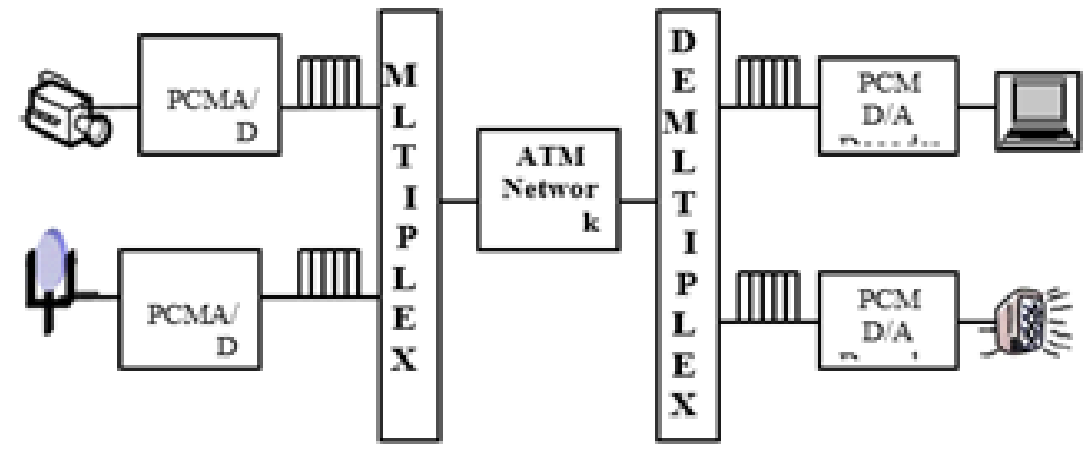

Figure 8. The block diagram of the design the ATM system

In the transmitter side, a microphone \& web digital camera device were used to generate the required information. The sound signal has sample rate equal to $8 \mathrm{KHZ}$, and with bit rate 64Kpbs. Image signal has, (400*356 pixels) type JPG (Joint Photographic Group), with12MHz sample rate. In this design image is converted to double size before compression to simplify dealing with the image signal. The bilinear transformation technique is utilized as compression technique of filter conversion from analog to digital. It is a standard technique of mapping the "s" or analog phase in to the " $\mathrm{z}$ " or digital phase. It converts analog filters, designed using classical filter design methods, into their discrete equivalents. Figure 9 shows bilinear transformation technique. After that the image and sound signals converted to digital by used A/D converter to make the ATM format, then multiplex the image and sound signals, and finally send the multiplexed signal to the network. Figure 10 presents the flowchart that illustrates the required stages for image and sound transmitter.

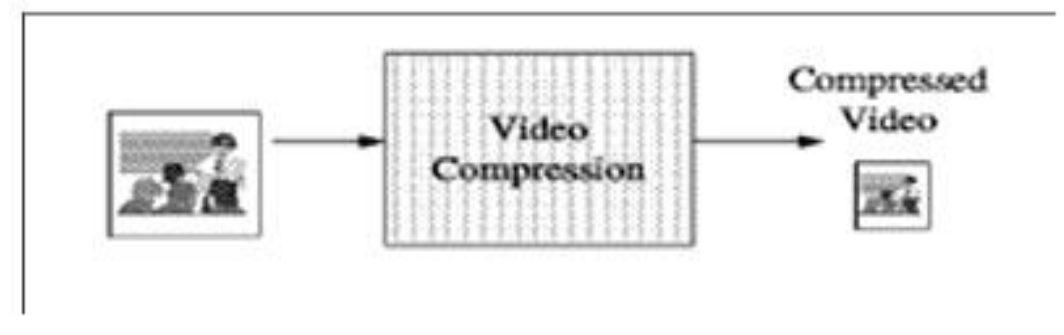

Figure 9. Bilinear transformation method

As shown in Figure 10, if the successful transmission is true, then the transmission is ended. Otherwise if the result is false, then the flowchart will return to the send movie stage. The decision processes this successful transmission is illustrated in Figure 11. The transmitted frame will consist of 47 bytes for image signal and one byte for sound signal. Then an additional necessary information is added which represents the address and check sum. The Figure 12 present flow chart illustrates process transfer the framing into ATM network. And Figure 13 illustrates the frame delivering after multiplexing.

The purpose from using check sum is to detect the error in the higher layer, in the sender, the data unit subdivided into an equal segment using the check sum generator. Utilizing one's complement arithmetic, the segments can be added together. Accordingly, the overall sum is complemented and then attached end unit of the original data as a as redundancy bits. After that the extended data unit is transmitted across the network. Figure 14 presents flowchart of the error detection method using check sum.

When the receiver gets the transmitted from, it adds the data unit and check sum header. If the result is all 1s the data unit is accepted; otherwise it is discarded. And then, the receiver checks the address, filed. If it is accepted, then it performs De-multiplex the data and store the result to obtain an image and sound. If the checking process for the message error, then the steps are repeated, otherwise it will save the data in the buffer as shown in Figure 15. 


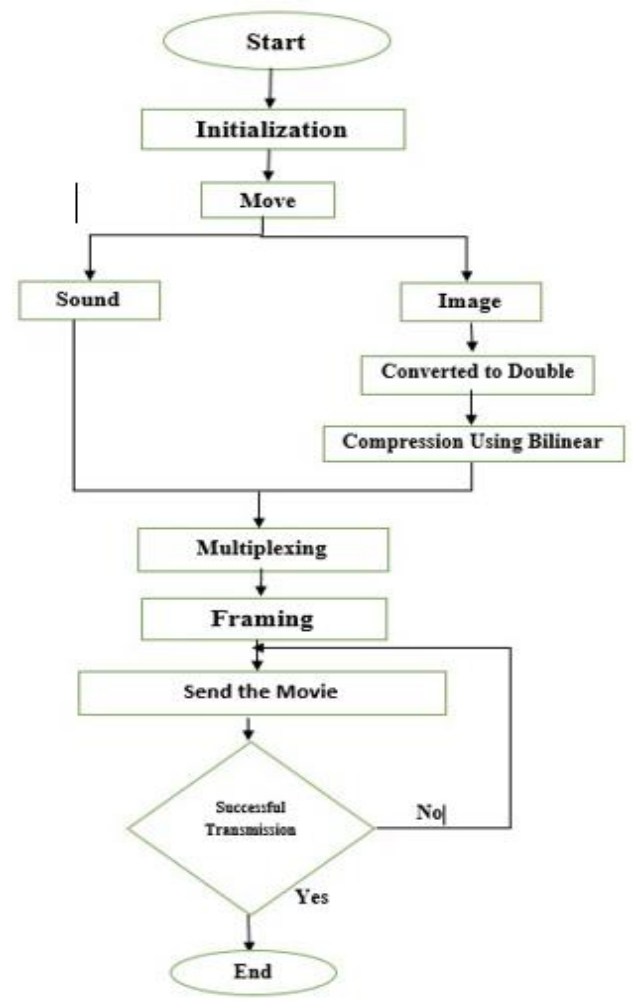

Figure 10. Flowchart illustrate transmission the stages for image and sound

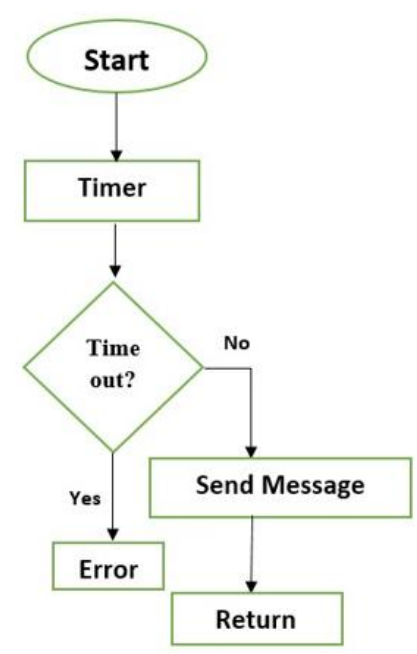

Figure 11. Illustrates if the send is successful or not

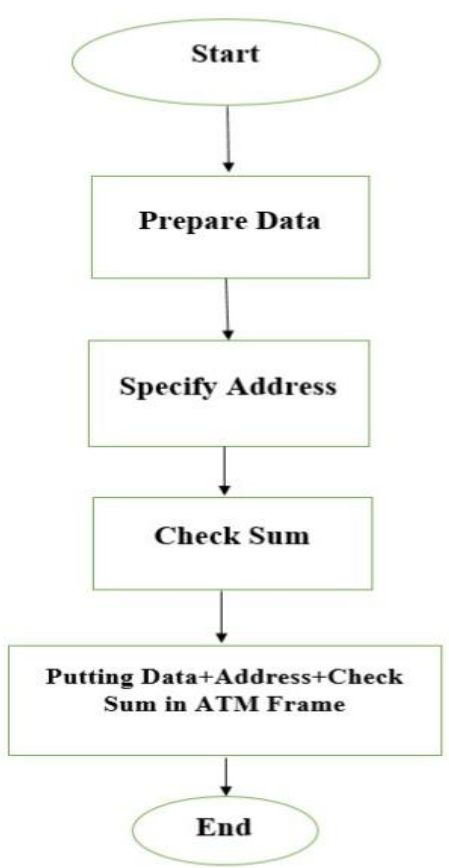

Figure 12. Flow chart illustrates process to transfer the framing into ATM network

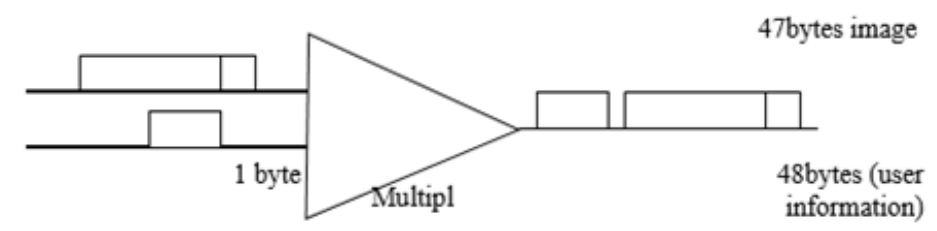

Figure 13. Illustrates frame delivering after multiplexing 


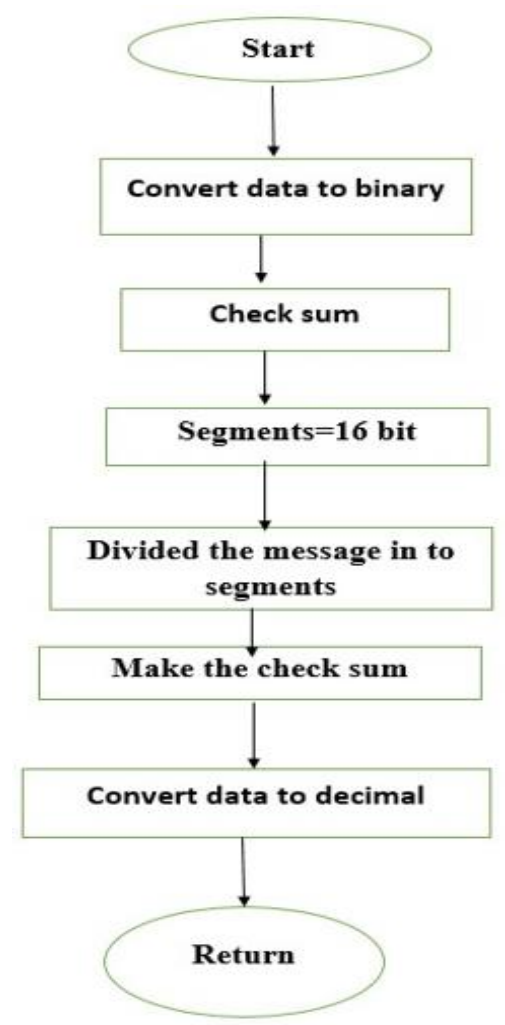

Figure 14. Illustrates check sum method

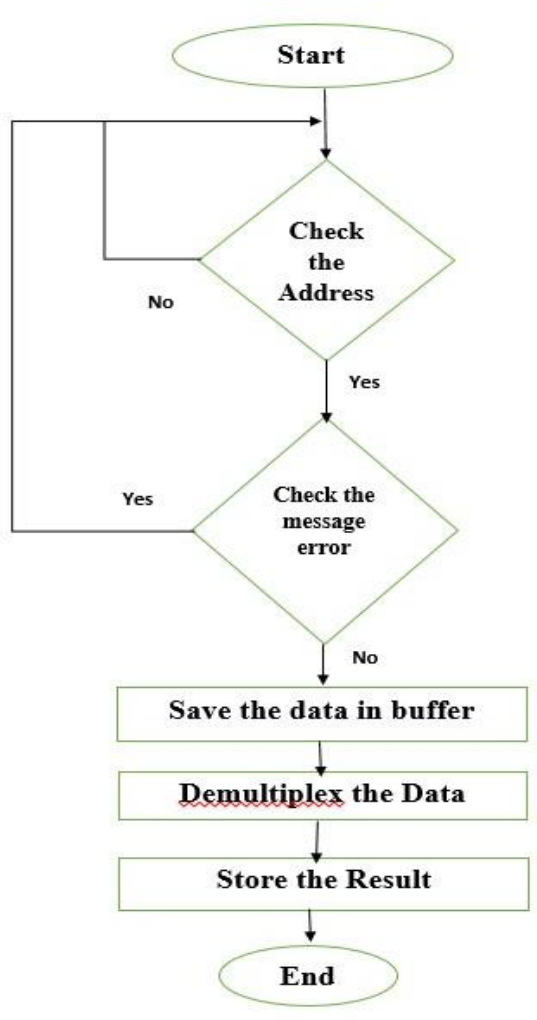

Figure 15. Illustrates receiver stage

\subsection{Hardware implementation of the prototype multimedia for distance learning}

To demonstrate the process of transferring sound \& image signal using ATM technique, a written program using Visual Basic language (VB) was implemented. This main page consists of the transmitter and receiver PCs. In the transmission side, an audio \& image signal is multiplexed into ATM frame then this frame is passed through a channel to the other side. In the receiver side, the opposite processing is carried out to get the sound \& image signal which must be similar to the transmitted signals. The proposed written program is an assistance program to clarify how an ATM frame is generated and received. Illustrates the details process of ATM technique shown in Figure 16.

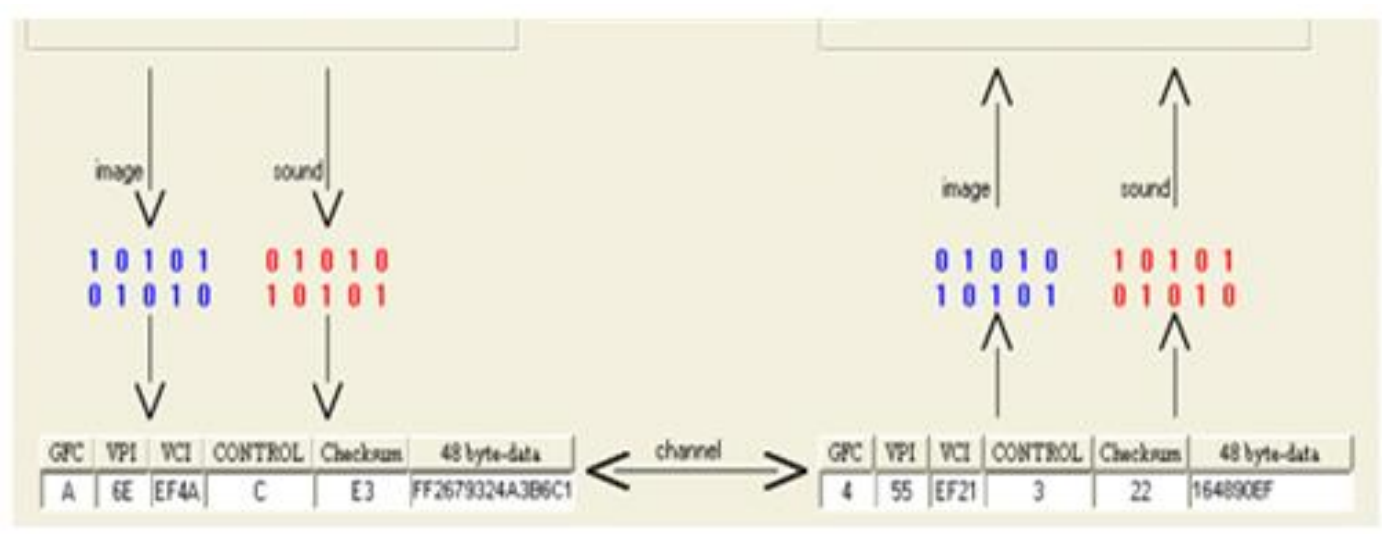

Figure 16. Illustrates the details process of ATM technique

\section{RESULTS \& DISCUSSION}

\subsection{Time delay calculations}

Consider Time Delay one of operation important to calculate performance of ATM. The following steps are applied to calculate (Time Delay). 


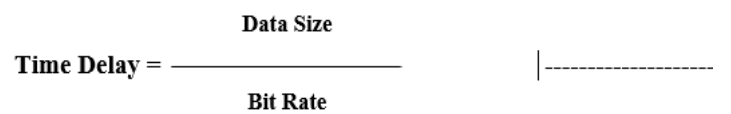

Where:-

Data Size $=$ user data + header $=53$ bytes

The change bit rate from (155.52Mbps to $622.82 \mathrm{M} \mathrm{bps).} \mathrm{Can} \mathrm{be} \mathrm{chosen} \mathrm{because} \mathrm{this} \mathrm{actual} \mathrm{speed} \mathrm{of} \mathrm{ATM}$ transmitter. Using (1) helps to calculate Time Delay for one cell as indicated in Table 1 and Figure 17 illustrates a curve which presents the change in the Time Delay with the change of the bit-rate in one cell. From the results shown in the Table 1 and Figure 17, it is obvious that the time delay in the ATM system is very limited. This means that the ATM system has a strong feature compared with other asynchronous communication systems. The effect of including integration video/voice traffics, these shown when send multimedia over ATM network for software design has been connected and used to measure the size of message sent. thus, the message size has been taken from integrated multimedia service video/voice, measuring the size of the message to enable the measure of the number of cells, and the size that obtained from ATM design system is equal to $(312.520 \mathrm{~K}$ byte), since ATM system uses the ATM adaptation layer 5 , which can convert the submitted information into 48 bytes segments, thereby dividing the size of messages obtained from the design by 48byte. Then to calculate time delay from this message has obtained to draw the curves that represent the variations in the time delay with the variations of the bit-rate hence, calculating time delay from the obtained message as shown in Table 2, and the curve is drawn as illustrated in Figure 18.

Table 1. The changes of bit-rate for one cell

\begin{tabular}{cc}
\hline Bit-rate/M bit/s & Time delay/ $\mu$ sec. \\
\hline 155.52 & 2.726 \\
207.36 & 2.044 \\
259.2 & 1.635 \\
311.04 & 1.363 \\
362.88 & 1.168 \\
414.72 & 1.022 \\
466.56 & 0.908 \\
518.4 & 0.817 \\
570.24 & 0.743 \\
622.08 & 0.681 \\
\hline
\end{tabular}

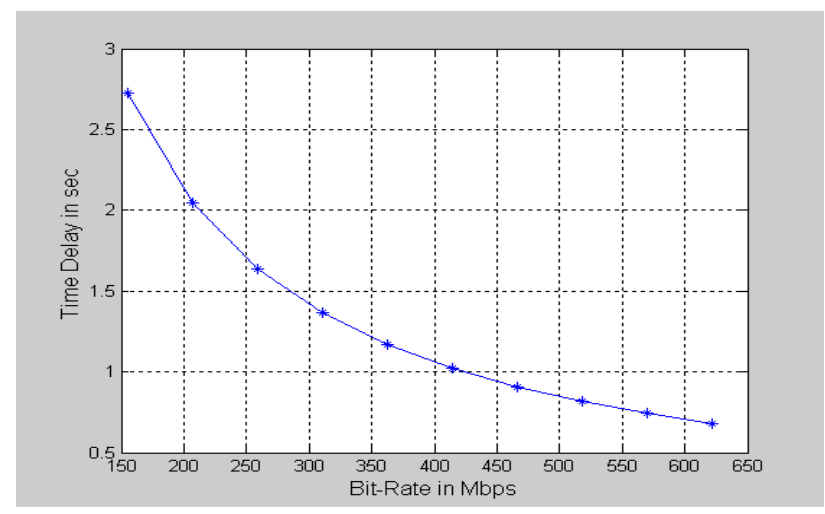

Figure 17. Illustrates the changes in the time delay with the changes of the bit-rate for one cell

Table 2. Time delay from the message

\begin{tabular}{cc}
\hline Bit-rate/M bit/s & Time delay/sec. \\
\hline 155.52 & 0.0177 \\
207.36 & 0.0133 \\
259.2 & 0.01065 \\
311.04 & 0.00887 \\
362.88 & 0.00760 \\
414.72 & 0.00666 \\
466.56 & 0.0059 \\
518.4 & 0.00532 \\
570.24 & 0.00484 \\
622.08 & 0.00444 \\
\hline
\end{tabular}

Indonesian J Elec Eng \& Comp Sci, Vol. 20, No. 2, November 2020 : 1016 - 1029 


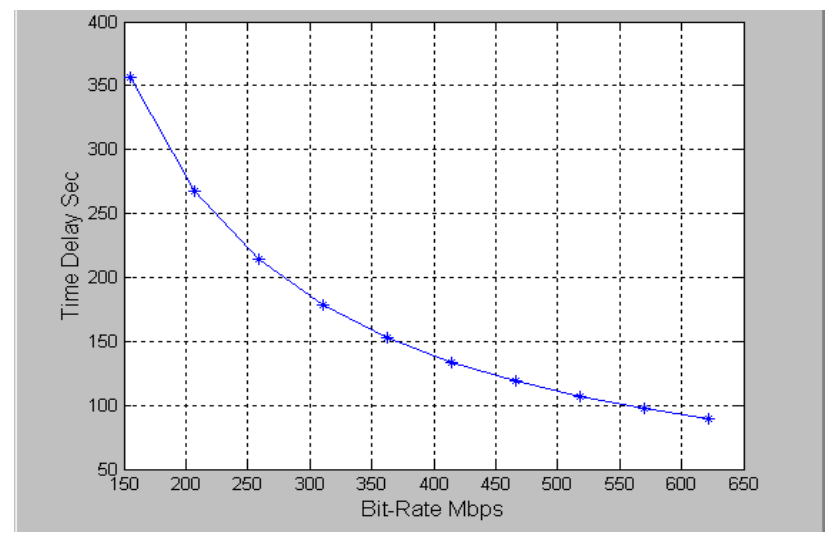

Figure 18. Illustrates the changes in the time delay with the changes of the bit-rate from the obtained message

\subsection{Throughput calculation}

It is called "good put", bit per second delivered to the application, through put rate is the time average for transporting the users' information from node to node in the network. The through put rate can be calculated by the results obtained from the time delay, calculation as follow. Table 3 and Figure 19 illustrate the results as obtained between payload and time delay.

\section{Number of information bits}

\section{Throughput $=$}

Total Time required to get those bits

Table 3. Results as obtained between payload and time delay

\begin{tabular}{cc}
\hline Time Delay/Sec & Throughput/bps \\
\hline 0.0177 & 216949 \\
0.0133 & 28872.2 \\
0.01065 & 36056.3 \\
0.00887 & 43291.9 \\
0.00760 & 50526.3 \\
0.00666 & 57657.6 \\
0.0059 & 65084.7 \\
0.00532 & 72180.4 \\
0.00484 & 79338.8 \\
0.00444 & 86486.4 \\
\hline
\end{tabular}

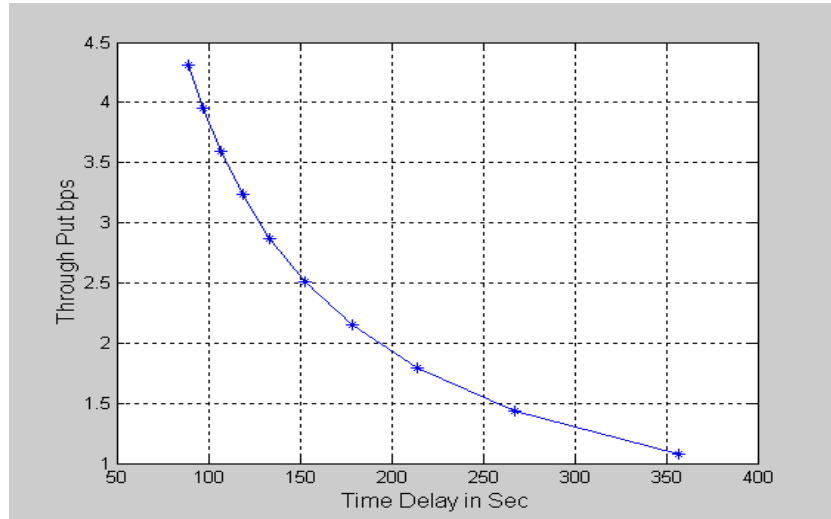

Figure 19. Illustrates through put VS. time delay 
From the obtained result and the curve in Figure 19 it is clear that the through put rate in the ATM systems is high, this fact gives the ATM system another robust feature hence, adaptation of these parameters allows the ATM networks to support the applications of multimedia with acceptable performance.

\subsection{Efficiency calculations}

Efficiency $(\eta)$ is the count of the helpful information of bytes divided by the overall bytes numbers. $[3,27]$ The following steps are followed to calculate the efficiency of the ATM system.

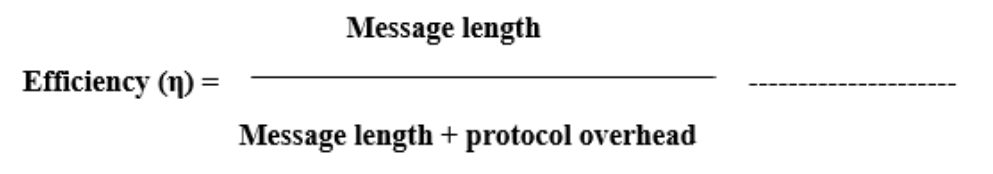

Message length $=$ user information (payload)

Protocol overhead $=$ AAL header + Cell header

Hence the cell in the ATM is fixed

Message length + protocol overhead $=53$ bytes for one cell.

To calculate efficiency of the obtained message when send (video/ audio) after multiplexing, its equal $312.52 \mathrm{~K}$ byte, the following results are obtained:

\section{Message length $=312.52 \mathrm{~K}$ byte \\ Message length + protocol overhead $=\mathbf{3 4 5 0 7 4}$ byte}

$$
\text { Efficiency }(\eta)=\frac{312.52 \mathrm{~K}}{345074}=90.5 \text {; }
$$

According to the results gained from efficiency calculation, it is clear how the ATM has managed to enhance network efficiency. It provides good transfer for multimedia and good method used for E- distance learning in the department of electricity and for all departments at the university of technology.

\section{CONCLUSIONS}

The ATM is one of the promising network technologies that is targeted for different data traffic as voice or video. This paper conducts different number of simulations to determine the ATM effectiveness with multimedia applications in the context of distance learning ad provides a propsed design tht tackles the issue of noise to maximize the thoughput and reduce delay. The simulations show the dependability of the network performance on specific system parameters which are tunable according to multimedia application that the ATM is used for. Such parameters are throughput, efficiency and time delay. Obtained results demonestrte that the porpsed design can fulfill the requirements of the E-learning system in terms of image/sound/video quality. The implemented system manages to mitigate the burden of noise on the quality of multimedia lectures broadcasted over ATM network.

\section{REFERENCES}

[1] Al-Adhaileh M, Al Fridan A. "A flexible distance education delivery model: Design and implementation at King Faisal University.” In 2015 Fifth International Conference on E-Learning (ECONF), pp. 312-315. IEEE, 2015 Oct 18.

[2] Frigon, J.F., Leung, V.C.M. and Chan, H.C.B. "Dynamic reservation TDMA protocol for wireless ATM networks."IEEE Journal on Selected Areas in Communications, vol. 19, no. 2, pp. 370-383, 2001.

[3] Cisco systems, "Asynchronous Transfer Mode (ATM) Fundamentals". International Engineering consortium, atalyzing Progress in the information-industry \& University Communication, 2005.

[4] Anthony Alles, "ATM Internetworking". Cisco systems, INC. email:aalles@ cisco.com, 2002.

[5] Yang Y, Tian D, Wu L. "Influence analysis of mobile learning research on modern distance education." In 2016 2nd IEEE International Conference on Computer and Communications (ICCC), pp. 883-886. IEEE, 2016 Oct 14.

[6] Laksitowening KA, Yanuarifiani AP, Wibowo YF. "Enhancing e-learning system to support learning style based personalization." In 2016 2nd International Conference on Science in Information Technology (ICSITech), pp. 329-333). IEEE, 2016 Oct 26.

[7] Mansor, N.A., Abdullah N., Rahman, H.A, "Towards electronic learning features in education 4.0 environment: literature study." Indonesian Journal of Electrical Engineering and Computer Science (IJEECS), vol. 19, no. 1, pp. 442-450, 2020. 
[8] Varner, L.W, "Student Perceptions of Interactive Distance Learning Program." Southeastern Teacher Education Journal, vol. 2, no. 2, 2009.

[9] Shahabadi MM, Uplane M. "Synchronous and asynchronous e-learning styles and academic performance of elearners." Procedia-Social and Behavioral Sciences, vol. 176, pp. 129-38, 2015 Feb 20.

[10] Perveen A. "Synchronous and asynchronous e-language learning: A case study of virtual university of Pakistan." Open Praxis, vol. 8, no. 1, pp. 21-39, 2016 Mar 3.

[11] Mustikaningrum, Desita, and Astari Retnowardhani. "Usability of BLESS-implemented class room: a case study of mixtio." TELKOMNIKA (Telecommunication, Computing, Electronics and Control) vol. 17, no. 2, pp. 703-711, 2019.

[12] Sadikin, Mujiono, Raka Yusuf, and Arif D. Rifai. "Load balancing clustering on moodle LMS to overcome performance issue of e-learning system." TELKOMNIKA (Telecommunication, Computing, Electronics and Control), vol. 17, no. 1, pp. 131-138, 2019.

[13] Pathi, Radhika, G. V. Rao, P. Rama Krishna, and P. Bharath Kumar. "Development of a Modular Unit of a Higher Level Framework or Tool for Basic Programming Course Teaching Through E-learning Mode, TELKOMNIKA (Telecommunication, Computing, Electronics and Control), vol. 16, no. 6, 2018.

[14] Al-Hamadani, M.N., Sattam, I.A., Daoud, R.W., Shehab, S.N. and Kamel, H.A, "Design and implement a selfmanaged computer network for electronic exams and sharing." Indonesian Journal of Electrical Engineering and Computer Science (IJEECS), vol. 19, no. 1, pp. 466-475, 2020.

[15] Ouatik, F., Raoufi, M., El Mohadab, M., Ouatik, Far., Bouikhalene, B., Skouri, M, "Modeling collaborative practical work processes in an e-learning context of engineering electric education." Indonesian Journal of Electrical Engineering and Computer Science (IJEECS), vol. 16, no. 3, pp. 1464-1473, 2019.

[16] Bin Rodzman, Sh. B., Abu Bakar, N., Choo, Y.H., Aljunid, S. A., Ismail, N.K., Abd Rahman, N., Rosli, M. M, "I-OnAR: A rule-based machine learning approach for intelligent assessment in an online learning environment." Indonesian Journal of Electrical Engineering and Computer Science (IJEECS), vol. 17, no. 2, pp. 1021-1028, 2020.

[17] Yang, L.T., Guo, M., Gao, G.R. and Jha, N.K. eds, "Embedded and Ubiquitous Computing," International Conference EUC 2004, Aizu-Wakamatsu City, Japan, Proceedings Vol. 3207, Springer, August 25-27, 2004.

[18] Behrouz A. Forouzan, "Data communication and networking", 3rd Edition, 2004.

[19] William Stallings, "High-Speed network: TCP/IP and ATM Design Principles". Prentice Hall PTR, London, 1998.

[20] Raleigh Center, "IBM Networked video solution over ATM Implantation". International Technical support organization, printed In New York, May 1997.

[21] Michael O. \& Peter S, "ATM \& MPEG-2", Prentice Hall PTR, London 1998.

[22] Reem Adnan H, "Design Flow Control Algorithm for ATM Network" M.SC, thesis, computer \& software Department, University Of Technology, Baghdad, 2004.

[23] Rangan P.V. \& Kumar S., "continuity and synchronization in MPEG". IEEE J, on selected Area in communication vol. 14, no. 1, Jan 1996.

[24] Telecom Alcatel, "Asynchronous Transfer Mode", AND-SA/ MKTY-HLB, http://wwwAlcatel.com, 2001.

[25] Wang David, "Multimedia over ATM", Advanced data networks [EE6364], NadaKishore Rmaswamy 2003.

[26] McManus Jean M. \& Keith, W., "Video on Demand over ATM: Constant rate transmission and transport". IEEE Journal in Communication, August 1996.

[27] Locken, H. A.,"Asynchronous Transfer Mode Fundamentals", Galina pildush published, 2002. 